\title{
Treatment of multiple sclerosis with IVIg: potential effects and methodology of clinical trials
}

\author{
Per Soelberg Sørensen
}

\begin{abstract}
There is extensive evidence that immune mechanisms are involved in the pathogenesis of multiple sclerosis (MS). A potential treatment effect of IVIg in MS could be mediated by several mechanisms as IVIg is able to modulate the immune response in different ways. The evidence of the effect of IVIg in MS is at present based on the results of small open trials, some of which have been encouraging. Confirmation of a beneficial effect of IVIg must await the results of placebo-controlled, double-blind trials. A placebo-controlled, crossover study of IVIg is being conducted using magnetic resonance imaging (MRI) for monitoring disease activity. However, the ultimate proof of efficacy must come from studies of parallel groups with large numbers of patients followed for long periods with repeated clinical observations of neurological function, for example, the Expanded Disability Status Scale (EDSS) or the Neurological Rating Scale (NRS).
\end{abstract}

Multiple sclerosis (MS) is a chronic disease in the central nervous system characterised by recurrent episodes of neurological dysfunction with more or less complete remission. The typical lesions in MS are characterised by perivascular foci of inflammation and demyelination. The aetiology is unknown but there is accumulating evidence implicating an interaction of genetically susceptibility with an environmental factor, possibly a virus. There is extensive evidence that immune mechanisms are involved in the pathogenesis of MS. An early feature of the acute MS attack is a disruption of the bloodbrain barrier causing a leak of immune mediators into the central nervous system. Complement activation, intrathecal antibody synthesis and the release of pro-inflammatory cytokines are involved in the immune response directed against oligodendrocyte surface and myelin proteins, which subsequently leads to disruption and phagocytosis of myelin by macrophages.

\section{Potential effects of IVIg}

Signs of immunological disturbances have been observed in MS patients, ${ }^{12}$ but it remains unclear which of these abnormalities play a primary role in the pathogenesis and which represent only an epiphenomenon. The aberrations include: 1) Changes in peripheral blood lymphocytes: a subpopulation of CD4 helper/inducer cells, which stimulates CD8 cells is reduced in chronic progressive MS. This is consistent with the finding of reduced percentage of CD8 cells in active MS. Activated T-cells expressing IL-2 receptors have been found increased in some but not all studies; ${ }^{3}$ 2) In cell culture, IgG synthesis by unstimulated B-cells is increased in MS, especially during active disease, and the response is enhanced by stimulation with pokeweed mitogen-a $\mathrm{T}$ cell dependent $\mathrm{B}$ cell activator. The response of $B$-cells to pokeweed mitogen can be weakened by stimulation of $T$ cells with concanavalin $A ; 13$ ) In CSF pleocytosis is mainly due to an increase in the number of CD4 cells. The majority of MS patients have cells in CSF producing IgG antibodies against myelin and myelin basic protein. The CSF concentration of IL-2, soluble IL-2 receptor and TNF $a$ correlates with the onset of exacerbation and disease progression. ${ }^{4}$

The potential effects of IVIg could be mediated by several mechanisms. ${ }^{5}$ IVIg from large pools of normal donors may contain anti-idiotypic antibodies which can: 1) neutralise circulating autoantibodies against myelin proteins; 2 ) interact with $\mathrm{V}$ regions of autoantibodies, selectively stimulate autoreactive B cell clones that are capable of idiotypic interactions with $\mathrm{V}$ regions of IVIg, and thus restore the physiological pattern of spontaneous fluctuations of the concentration of autoantibodies in plasma; 3 ) bind to specific epitopes of the $\mathrm{T}$-cell receptor of certain regulatory $\mathrm{T}$-cells and thereby cause suppression of inducer T-cells and B-cells. ${ }^{6}$

Furthermore, IVIg can downregulate cytokine production and/or neutralise inflammatory cytokines (IL-1, IL-2, IL-6, INF- $\gamma$, and IL-2 receptor). ${ }^{7}$ IVIg may act as receptor for activated complement components by preventing their attachment to oligodendrocyte surface and myelin proteins, ${ }^{8}$ and IVIg may modulate $\mathrm{Fc}$ receptors on macrophages. ${ }^{9}$

\section{Previous studies of IVIg in MS}

In early uncontrolled studies IVIg has been used as treatment for acute exacerbations in MS and for control of disease progression (table). Rothfelder et $a l^{10}$ treated 20 patients with relapsing-remitting MS with IVIg $5 \mathrm{~g}$ 
Clinical trials of IVIg in multiple sclerosis

\begin{tabular}{|c|c|c|c|c|c|c|}
\hline Trial & Design & Patients & $N$ & $I V I g$ & Efficacy parameter & Results \\
\hline $\begin{array}{l}\text { Rothfelder, } \\
\text { et al, } 1982^{10}\end{array}$ & $\begin{array}{l}\text { Open, } \\
\text { uncontrolled }\end{array}$ & $\begin{array}{l}\text { Relapsing- } \\
\text { remitting }\end{array}$ & 20 & \multirow{4}{*}{$\begin{array}{l}5 \mathrm{~g} / 2 \text { month } \\
\text { for } 12 \text { months } \\
5 \mathrm{~g} / \mathrm{week} \text { for } 3-4 \text { years } \\
(\sim 0.3 \mathrm{~g} / \mathrm{kg} / \mathrm{month}) \\
50 \mathrm{mg} / \mathrm{kg} / \text { day } \\
\text { for } 2-3 \text { weeks } \\
2 \mathrm{~g} / \mathrm{kg} / 2 \text { months } \\
\text { for } 12 \text { months }\end{array}$} & $\begin{array}{l}\text { Clinical symptoms } \\
\text { Fog Scale }\end{array}$ & \multirow{4}{*}{$\begin{array}{l}\text { Significant } \\
\text { reduction } \\
1 / 3 \text { improved } \\
1 / 3 \text { stable } \\
62 \% \text { improved }\end{array}$} \\
\hline $\begin{array}{l}\text { Schuller, } \\
\text { et al, 1983"1 }\end{array}$ & $\begin{array}{l}\text { Open, } \\
\text { uncontrolled }\end{array}$ & Definite MS & 31 & & $\begin{array}{l}\text { Disability } \\
\text { Kurtzke Scale }\end{array}$ & \\
\hline $\begin{array}{l}\text { Soukop, } \\
\text { et al, } 1986^{12}\end{array}$ & $\begin{array}{l}\text { Open, } \\
\text { uncontrolled }\end{array}$ & $\begin{array}{l}\text { Acute } \\
\text { exacerbation }\end{array}$ & 22 & & Clinical symptoms & \\
\hline $\begin{array}{l}\text { Achiron, } \\
\text { et al, 1992 }\end{array}$ & $\begin{array}{l}\text { Open, } \\
\text { controlled }\end{array}$ & $\begin{array}{l}\text { Relapsing- } \\
\text { remitting }\end{array}$ & 10 & & Exacerbation rate & \\
\hline
\end{tabular}

every second month for 12 months. They reported a significant reduction in symptoms, reflected by a decrease in the score on the Fog Scale from $28 \cdot 8$ to $21 \cdot 3$. Further, a reduction in exacerbation rate was found in the treatment period compared with the rate during the year before IVIg therapy.

Schuller and Govaerts ${ }^{11}$ treated 31 moderately disabled MS patients (mean Kurtzke score 4) with IgG. All patients initially received intramuscular injections of gammaglobulin $5 \mathrm{~g}$ three times a week for at least one year. Later they used IVIg $5 \mathrm{~g} /$ week (equals $0.3 \mathrm{~g} / \mathrm{kg} / \mathrm{month}$ ). The treatment was continued for a mean period of four years. Overall, one third improved, one third were stable and one third deteriorated.

IVIg was used for treatment of acute exacerbations by Soukop and Tschabitscher ${ }^{12}$ in a study of 27 patients of whom 22 had a relapsing-remitting type and five had a primary progressive type of MS. IVIg was administered in small doses $(50 \mathrm{mg} / \mathrm{kg}$ ) during an acute exacerbation or progression for a period of two to three weeks. In $16(62 \%)$ of the patients IVIg treatment resulted in improvement in neurological score, usually within 24 hours.

Recently, Achiron et $a l^{13}$ treated 10 patients with relapsing-remitting $M S$ with IVIg $0.4 \mathrm{~g} / \mathrm{kg} /$ day for five days followed by 0.4 $\mathrm{g} / \mathrm{kg}$, once every two months, for 12 months. Ten untreated patients matched for age and disease characteristics served as controls. A significant decrease in attack frequency was seen in IVIg treated patients from $3.7(1.2)$ in the year before treatment to $1 \cdot 0(0 \cdot 7)$ per year during IVIg treatment, whilst it remained unaltered in the controls. No significant difference was found in change in the Kurtzke EDSS score between the two groups.

\section{Methodology of clinical trials of IVIg in MS}

These initial studies of IVIg treatment in MS demonstrate the difficulties in the evaluation of results of clinical trials of MS using disability rating scales as a measure of efficacy. Such studies require large numbers of patients treated for long periods. Several recent MRI studies have shown that even "stable" relapsing-remitting MS run a more chronically active course than previously recognised, and measuring only clinical exacerbations may be misleading. In relapsing-remitting or relapsing-progressive MS the average clinical relapses per year is $0.5-1.0$ compared with
3-5 new MRI lesions per year, ${ }^{14}{ }^{15}$ and the deterioration in EDSS averages $0.5-1.0$ per two years. Moreover, changes in EDSS are dependent on the baseline EDSS: patients with an EDSS 0-2 progress $>1.0$ units, while patients with an EDSS 3-6 progress $<0.5$ units in a two year trial. ${ }^{16}$ Thus it appears that the evaluation of disease activity using MRI is a far more sensitive measurement of treatment response than changes in neurological function or disability. For example, a placebo-controlled trial with parallel groups with $2 p=0.05$ and a statistical power of $80 \%$ would need to include 80 patients if a $50 \%$ reduction in MRI activity is used as an efficacy parameter, while the number of patients required would be 200 if an increase in EDSS $\geq 1$ is used as an efficacy parameter.

For the study-design, crossover studies are more powerful than parallel group designs, the latter usually needing three to four times as many patients to achieve the same statistical power. For example, a placebo-controlled trial using MRI every four weeks in one year and a $50 \%$ reduction of MRI activity as outcome measure $(2 p=0.05$ and power $80 \%)$ would require 25 patients in a crossover trial and 100 patients in a trial with parallel groups. Unfortunately, in immunomodulatory treatments for MS the duration of the effect is unknown and, thus, it is difficult to determine the required length of the wash-out period between the two treatment periods in a crossover trial.

In crossover trials with frequent monitoring of Gadolinium-enhancing lesions, $M R I$ as outcome measure has advantages in pilot trials of new prospective drugs for treatment of MS, because the number of patients and the duration of treatment can be reduced.

\section{Design of a placebo-controlled, double- blind crossover study}

We have undertaken a randomised, placebocontrolled, crossover study of IVIg using serial MRI for evaluation of efficacy. Patients with relapsing-remitting course of $\mathrm{MS}$ with at least two clinical MS attacks within the previous 12 months or with progressive-relapsing disease with progression within the previous year are included. Half of the patients are treated with IVIg (Gammagard) $1.0 \mathrm{~g} / \mathrm{kg}$ body weight daily for two consecutive days at intervals of four weeks over a period of six months. After this, the patients will have a three month wash-out period without 
treatment, followed by six months of placebo treatment with an identical regime. The other half of the patients are treated with placebo followed by IVIg. The primary efficacy parameter is the number of new contrast enhancing lesions shown in serial MRI with intervals of four weeks during the treatment and control period. Secondary efficacy parameters are the number of clinical attacks, and changes in neurological function, for example, Neurological Rating Scale (NRS) and Expanded Disability Status Scale (EDSS). MRI is performed using a wholebody MRscanner at 1.5 Tesla with intravenous injection of Gadolinium-DPTA (Gd-DPTA). MRIs are evaluated "blind" and the number and size of lesions showing enhancement after injection of Gd-DPTA are measured. Statistical analysis will be performed using the Mann-Whitney U-test of the crossover study with two periods. The analysis is made with $2 p=0.05$, type 2 error $20 \%$, and the smallest relevant difference (Miredif) $=0.5$. With these preconditions, the required number of patients will be 22 .

\section{Conclusion}

At present, evidence for the efficacy of IVIg in the treatment of MS is based on a limited number of small open trials of which some have shown encouraging results. Assessment of efficacy must await the results of placebocontrolled, double-blind studies. A crossover trial with MRI for monitoring the treatment effect is ongoing and may provide evidence of the control of disease activity with IVIg treatment. However, the ultimate goal for treatment is to improve the clinical condition and function of the patients. Crossover trials using MRI changes as efficacy parameter should therefore be followed by studies of parallel groups with large numbers of patients followed for long periods with repeated clinical observations of neurological function, for example, EDSS or NRS.

1 Oger J, Kastrukoff LF, Li DK, Paty DW. Multiple sclerosis: in relapsing patients, immune functions vary with disease activity as assessed by MRI. Neurology 1988;38: 1739-44.

2 Hafler DA, Weiner HL. MS: a CNS and systemic autoimmune disease. Immunol Today 1989;10:104-7.

3 Selmaj K, Plater-Zyber KC, Rockett KA, et al. Multiple sclerosis; increased expression of interleukin 2 receptors on lymphocytes. Neurology 1986;36:1392-5.

4 Sharief MK, Hentges R. Association between tumor necrosis factor-alpha and disease progression in patients with multiple sclerosis. $N$ Engl F Med 1991;325:467-72.

5 Weiner HL, Hafler DA. Immunotherapy of multiple sclerosis. Ann Neurol 1988;23:211-22.

6 Tenser RB, Hay KA, Aberg JA. Immunoglobulin G immunosuppression of multiple sclerosis. Suppression immunosuppression of multiple sclerosis. Suppression 1993;50:417-20.

7 Anderson UG, Bjork L, Skansen-Saphir U, Anderson JP. Down-regulation of cytokine production and interleukin-2 receptor expression by pooled human IgG Immunol 1993;79:211-6.

8 Frank MM, Basta M, Fries LF: The effect of intravenous immune globulin on complement-dependent immune damage of cells and tissues. Clin Immunol Immunopatho 1992;62:S82-6.

9 Jungi TW, Breie M, Kuhnert P, et al. Effect of IgG for intravenous use on Fc receptor-mediated phagocytosis by human monocytes. Clin Exp Immunol 1990;82: 163-9.

10 Rothfelder U, Neu I, Pelka R. Therapy of multiple sclerosis with immunoglobulin G. MMW Munch Med Sis with immunoglobulin

11 Schuller E, Govaerts A. First results of immunotherapy with immunoglobulin $G$ in multiple sclerosis patients. Eur Neurol 1983;22:205-12.

12 Soukop W, Tschabitscher H. Gamma globulin therapy in multiple sclerosis. Theoretical considerations and initial clinical experiences with $7 \mathrm{~S}$ immunoglobulins in MS therapy. Wien Med Wochenschr 1986;136:477-80.

13 Achiron A, Pras E, Gilad R, et al. Open controlled therapeutic trial of intravenous immune globulin in relapsing remitting multiple sclerosis. Arch Neurol 1992;49. remittin

14 Willoughby EW, Grochowski E, Li DKB, Oger J, Kastrukoff LF, Paty D. Serial magnetic resonance scanning in multiple sclerosis: A second prospective study in ning in multiple sclerosis: A second prospective

15 Isaac C, Li DKB, Genton M, et al. Multiple sclerosis: a serial study using MRI in relapsing patients. Neurology 1988;38:1511-5.

16 Bornstein MB, Miller A, Slagle S, et al. A placebo-controlled, double-blind, randomized two-center, pilot trial of COP 1 in chronic progressive multiple sclerosis. Neurology 1991;41:533-9. 